This is the final peer-reviewed accepted manuscript of:

Gherardi, M.; Turrini, E.; Laurita, R.; De Gianni, E.; Ferruzzi, L.; Liguori, A.; Stancampiano, A.; Colombo, V.; Fimognari, C. Atmospheric Non-Equilibrium Plasma Promotes Cell Death and Cell-Cycle Arrest in a Lymphoma Cell Line. Plasma Processes and Polymers 2015, 12 (12), 1354-1363.

The final published version is available online at:

https://doi.org/10.1002/ppap.201500033.

Rights / License:

The terms and conditions for the reuse of this version of the manuscript are specified in the publishing policy. For all terms of use and more information see the publisher's website.

This item was downloaded from IRIS Università di Bologna (https://cris.unibo.it/)

When citing, please refer to the published version. 
((please add journal code and manuscript number, e.g., DOI: 10.1002/ppap.201100001)) Article type: Full Paper

\section{Atmospheric non-equilibrium plasma promotes cell death and cell-cycle arrest in a lymphoma cell line}

Matteo Gherardi*, Eleonora Turrini, Romolo Laurita, Elena De Gianni, Lorenzo Ferruzzi, Anna Liguori, Augusto Stancampiano, Vittorio Colombo*, Carmela Fimognari

Vittorio Colombo, Matteo Gherardi, Romolo Laurita, Anna Liguori, Augusto Stancampiano Department of Industrial Engineering (DIN), Alma Mater Studiorum-University of Bologna, Via Saragozza 8, 40123 Bologna, Italy

Email: vittorio.colombo@unibo.it; matteo.gherardi4@unibo.it

Vittorio Colombo

Advanced Mechanics and Materials, Interdepartmental Center for Industrial Research (AMM-ICIR), Alma Mater Studiorum-University of Bologna, Via Saragozza 8, 40123 Bologna, Italy

Lorenzo Ferruzzi, Carmela Fimognari, Eleonora Turrini

Department for Life Quality Studies, Alma Mater Studiorum-University of Bologna, Corso d'Augusto 237, 47921 Rimini, Italy

Elena De Gianni

Advanced Mechanics and Materials, Interdepartmental Center for Industrial Research (AMM-ICIR), Alma Mater Studiorum-University of Bologna, Piazza Malatesta, 29/30, 47923 Rimini, Italy

Atmospheric non-equilibrium plasma is drawing interest as a promising tool for cancer treatment due to its blend of physical and chemical components that can exert anti-tumor effects.

In this work, we investigate the effects of plasma treatment, performed by means of a wand electrode DBD driven by nanosecond high voltage pulses, on the viability, proliferation and cell-cycle distribution of cells of mouse lymphoma. Results for direct treatment, with cell exposed to plasma while suspended in culture medium, and indirect treatment, where cells were added to culture medium previously activated by plasma treatment, are compared. A qualitative characterization by means of high-speed and $\mathrm{ICCD}$ imaging of the plasma 
discharges produced for the different operating conditions adopted in biological experiments, as well as a semi-quantitative study of the reactive species produced by plasma treatment in the culture medium, are also presented.

\section{Introduction}

Despite improvements in survival rates, cancer is still the second leading cause of death in Western countries [1]. While the rapidly expanding knowledge of cancer pathogenesis at the molecular level is providing new targets for drug discovery and development, the multiple genetic and molecular alterations involving transformation, dysregulation of apoptosis, proliferation, invasion, angiogenesis and metastasis [2] make cancer an extremely complex disease.

Currently, the treatment of cancer largely revolves around chemotherapy, with new therapeutic approaches under investigation, alone or in combination with conventional chemotherapy. Despite the development of multiple new agents, antitumor therapies are strongly limited by the low therapeutic index of most of the adopted drugs and by the development of chemoresistence. In particular, the onset of chemoresistance frequently hampers the successful treatment of cancer either at the initial presentation or following primary or subsequent relapses [3], and relapse continues to be the most common cause of death [4]. Thus, cancer remains a formidable therapeutic challenge that requires the identification and the development of novel agents for the treatment of this disease.

Atmospheric non-equilibrium plasmas are encountering increasing interest as a novel antitumor agent, since they provide a blend of physical and chemical components (reactive species, charged particles and UV radiation) which was demonstrated to exert anti-tumor effects by some pioneering work both on in vivo and in vitro models [5,6]. However, the mechanism of plasma-cell interaction is still not completely understood, as well as the selectivity associated to the various plasma generated species. Different species were 
demonstrated to mediate either 'plasma-killing' (for the case of singlet oxygen, $\mathrm{O}$ ) or 'plasmahealing' (for the case of nitrogen oxide, NO) effects [7]. Gweon et al. [8] considered reactive oxygen species (ROS) responsible for the dissociation of integrin and the consequent detachment of human liver cancer cells (SK-HEP-1). Ishaq et al. [9] demonstrated that plasma treatment induced apoptosis in melanoma cells and, differently from the previous works, focused their attention on intracellular ROS levels. On the other hand, Volotskova et al. [10] demonstrated that plasma treatment enhances the oxidative stress of cells in the $\mathrm{S}$ phase of the cell cycle. Interestingly, recent studies [11] have reported that plasma not only affects cancer cells when they are directly exposed to it or suspended in the culture medium being treated, but also when they are subject to indirect treatment, being suspended in a medium that was previously treated and activated by plasma. Tanaka et al. [12] demonstrated that, when treated by plasma activated medium, glioblastoma human brain tumor cells were induced to undergo apoptosis, through AKT down-regulation; moreover, they also demonstrated in vitro and in vivo that plasma-activated medium has an anti-tumor effect on chemo-resistant epithelial ovarian carcinoma cells [13].

These observations together with the rapidly expanding knowledge of cancer biology have fueled a growing interest in exploiting cold plasma as an interesting strategy in the oncological field endowed with the potential of shifting the current paradigm of cancer treatment and enabling the transformation of cancer treatment technologies.

In this work, we focused on the fundamental mechanisms of plasma interaction with cancer cells, investigating cell viability, proliferation and cell-cycle distribution of L5178Y lymphoma cells treated by a wand electrode dielectric barrier discharge (DBD) [14] driven by unipolar nanosecond high voltage pulses [15]. Plasma direct treatment was performed keeping constant the electrical parameters (peak voltage and pulse repetition frequency), while adopting two different combinations of treatment time and gap width between the tip of the plasma source and the liquid; the differences between the plasma discharges generated in the 
considered operating conditions were highlighted and analyzed through iCCD and high speed (HS) imaging, which are often used for qualitative characterization of non-equilibrium plasmas [16-25]. Flow cytometry was employed to evaluate cell viability at 6, 24 and $48 \mathrm{~h}$ after plasma treatment, as well as to analyze cell-cycle distribution after cell culture for 24 and $48 \mathrm{~h}$. Finally, a comparison of the effects of direct and indirect treatments, where cancer cells are exposed to a previously plasma treated culture medium instead of being directly exposed to plasma treatment, and the semi-quantitative measurement of nitrites, nitrates and peroxides in the plasma treated medium were carried out to support the evaluation of the observed cell response to plasma exposure.

\section{Experimental Section}

\subsection{Plasma device}

The wand electrode DBD plasma source used in this work, represented in Figure 1, consists of a cylindrical brass electrode, with a $10 \mathrm{~mm}$ diameter, having a semispherical tip, with curvature radius of approximately $5 \mathrm{~mm}$. The electrode is covered with borosilicate glass (relative permittivity $\varepsilon_{\mathrm{r}}=4.7$ ) as dielectric layer with a thickness of $1 \mathrm{~mm}$. The plasma source is driven by a commercial pulse generator producing high voltage pulses with a slew rate of few $\mathrm{kV} / \mathrm{ns}$, a peak voltage (PV) of 7-20 kV into a 100-200 $\Omega$ load impedance and a maximum pulse repetition frequency (PRF) of $1000 \mathrm{~Hz}$.

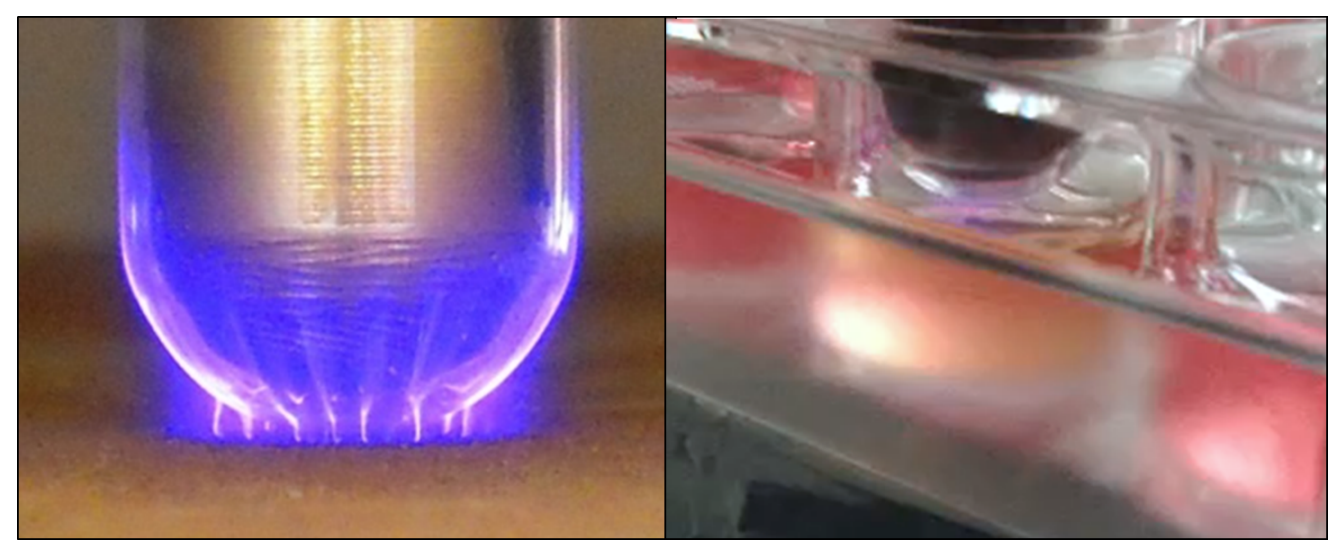

Figure 1. Wand electrode DBD discharge on a grounded plate (left) and on liquid culture medium during cell treatment (right). 


\subsection{Plasma device characterization}

A high-speed camera (Memrecam GX-3-NAC Image Technology) has been used to visualize the behavior of the plasma discharge in contact with $1 \mathrm{~mL}$ of Dulbecco's modified Eagle's medium (DMEM) contained in a 24 wells plate, representative of the operating conditions adopted for the treatment of cancer cells as later described in Paragraph 2.4; for these tests, the 24 wells plate was slightly modified, removing part of the plastic walls to allow an optimal visualization of the plasma region. Results will be presented for the camera being operated either at $500 \mathrm{fps}$ (frames per second) and 1/500 s shutter time or at $100 \mathrm{fps}$ and 1/100 s shutter time; as the shutter time was equal or superior to the pulse period, no means of synchronization was necessary. The setup adopted for high-speed imaging characterization is reported in Figure 2.

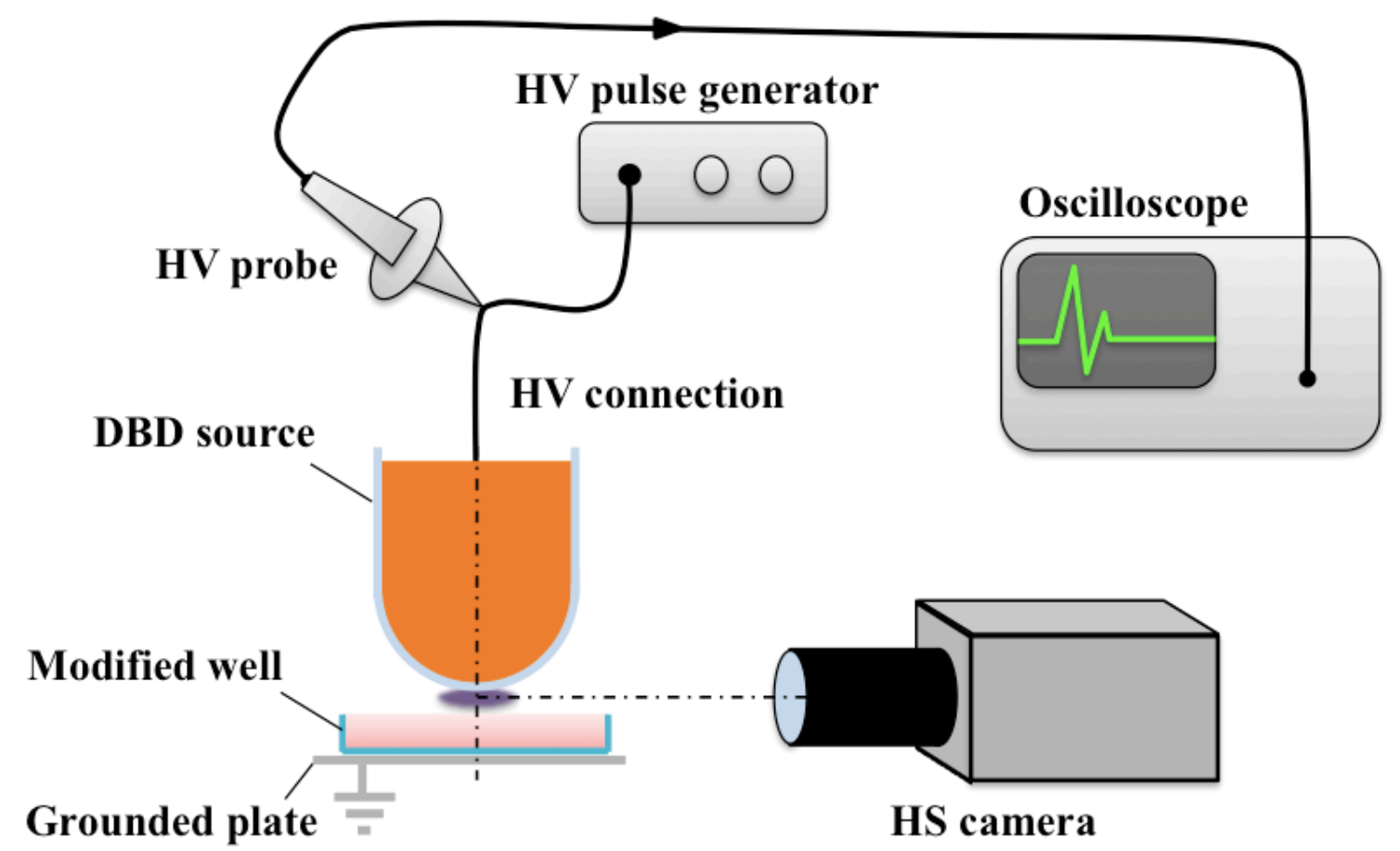

Figure 2. Representation of the setup for high speed imaging characterization of the wand electrode DBD discharge during the treatment of DMEM.

Temporal evolution of the plasma discharge in contact with DMEM has been investigated by means of an iCCD camera (Princeton Instruments PIMAX3). A synchronous pulse generator 
(BNC 575 digital pulse/delay generator) has been used to synchronize the high voltage generator and the oscilloscope (Tektronix DPO 40034) adopted to trigger the iCCD camera, as schematically represented in Figure 3; to allow an optimal visualization of the plasma region, the same modified 24 wells plate adopted for high speed imaging test was used for iCCD experiments. The plasma discharge temporal evolution during an entire pulse was reconstructed from sequential frames acquired at time steps of $1 \mathrm{~ns}$ and with an exposure time of $3 \mathrm{~ns}$.

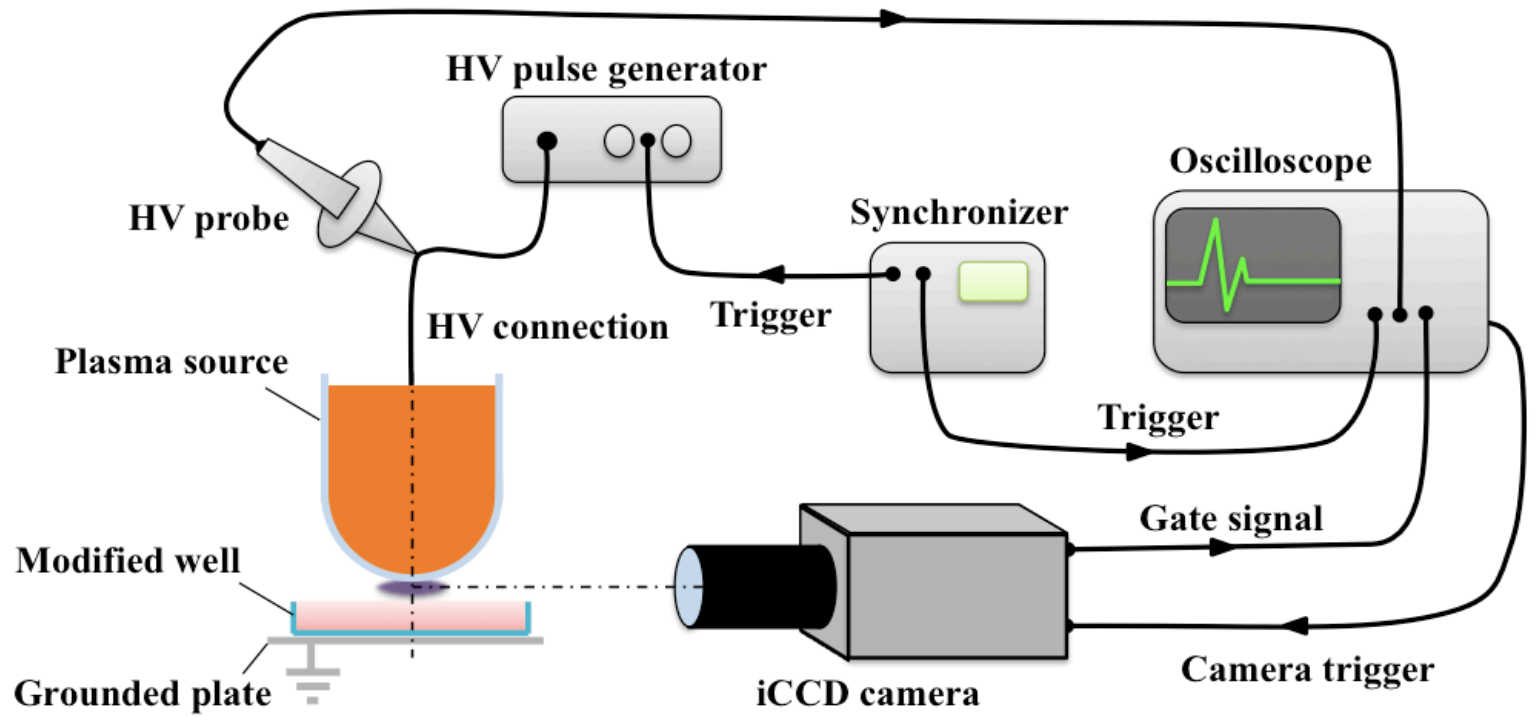

Figure 3. Representation of the setup for iCCD imaging characterization of the wand electrode DBD discharge during the treatment of DMEM.

\subsection{Cell cultures}

For the experiments, L5178Y TK+/- clone (3.7.2C) cells of mouse lymphoma (LGC Standard, Teddington Middlesex, UK) were grown in suspension and propagated in DMEM (from LGC Standard) supplemented with $4 \mathrm{mM}$ L-glutamine, $10 \%$ inactivated fetal bovine serum, $1 \%$ penicillin/streptomycin solution, $0.1 \%$ pluronic (all obtained from Sigma, St Louis, MO, USA). To maintain the exponential growth, the culture was divided every third day by dilution to a final concentration of $1-2 \times 10^{5}$ viable cells $/ \mathrm{mL}$. Cells were cultured at $37^{\circ} \mathrm{C} / 5 \%$ $\mathrm{CO}_{2}$ 


\subsection{Plasma treatment}

Plasma treatment of lymphoma cells was performed either in direct and indirect configuration. In direct configuration, $5 \times 10^{5}$ cells in $1 \mathrm{~mL}$ complete medium were seeded in a monolayer through centrifugation and directly exposed to plasma treatment in a 24 wells plate; two different sets of operating conditions have been considered: in the first case (T1), a $60 \mathrm{~s}$ treatment was performed keeping a $1.25 \mathrm{~mm}$ distance between the tip of the plasma source and the surface of the liquid medium (gap); in the second case (T2), a $120 \mathrm{~s}$ treatment was performed setting the gap at $2.50 \mathrm{~mm}$. During the experiments, PV and PRF were kept constant at $20 \mathrm{kV}$ and $500 \mathrm{~Hz}$ respectively. These two operating conditions were selected after a series of preliminary tests; in particular, for each of the two mentioned gaps, preliminary treatments were performed for several different treatment times, after which cell viability was assayed: we selected the operating conditions that resulted in a significant reduction of cell viability, but still higher than $50 \%$ (normalised to the cell viability of untreated cells), necessary to perform the cell proliferation experiments.

In indirect configuration, $1 \mathrm{~mL}$ of complete medium not containing lymphoma cells was exposed to plasma treatment in a 24 wells plate; 500000 lymphoma cells were added to the medium immediately after plasma treatment. A comparison of the effects of direct and indirect treatments was carried out for the following operating conditions: PV $20 \mathrm{kV}$, PRF $500 \mathrm{~Hz}$, gap $1.25 \mathrm{~mm}$ and various treatment times $(30 \mathrm{~s}, 45 \mathrm{~s}, 60 \mathrm{~s}, 90 \mathrm{~s}$ and $120 \mathrm{~s})$.

Setups for direct and indirect treatments are schematically reported in Figure 4A and Figure 4B respectively. 

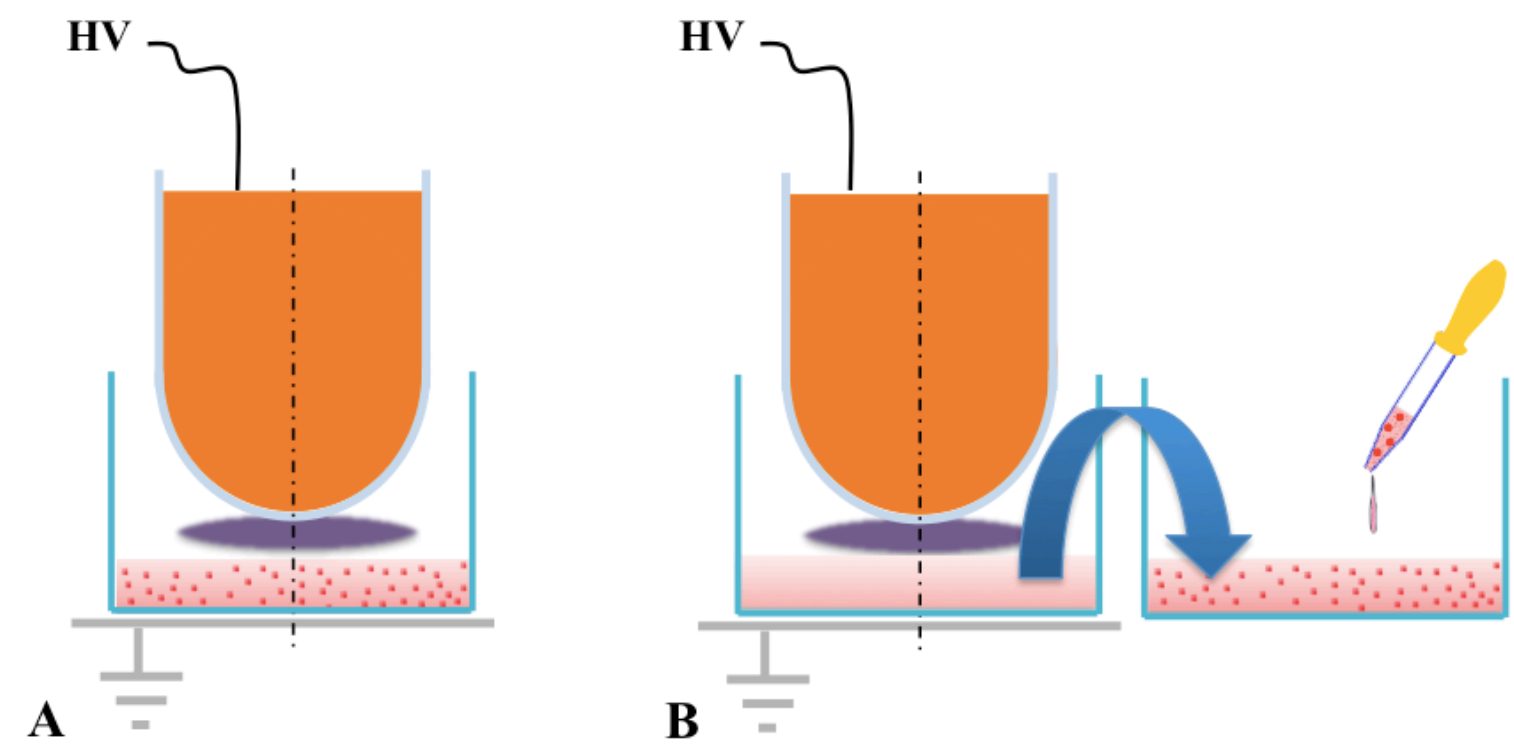

Figure 4. DBD plasma treatment of lymphoma cells: A) direct treatment setup; B) indirect treatment setup.

\section{Biological assays}

For direct treatment, cell viability and proliferation were determined after 6, 24 and $48 \mathrm{~h}$ from atmospheric non-equilibrium plasma exposure of cells at the two different experimental conditions; for the comparison between direct and indirect treatments, cell viability was determined after 6, 24 and $48 \mathrm{~h}$ from atmospheric non-equilibrium plasma exposure of cells (direct treatment) or 6, 24 and $48 \mathrm{~h}$ after cells were added to the plasma treated culture medium (indirect treatment). Briefly, $25 \mu \mathrm{L}$ of cell suspension were mixed with $225 \mu \mathrm{L}$ of Guava ViaCount Reagent (Merck Millipore, Hayward, CA, USA) containing 7aminoactinomycin D (7-AAD), a fluorescent intercalator of DNA, and incubated in the dark at room temperature for $5 \mathrm{~min}$ before the flow cytometric analysis, performed using the guava easyCyte 5HT (Merck Millipore).

To evaluate cell-cycle distribution, cells were treated at the two established experimental conditions and cultured for 24 and $48 \mathrm{~h}$, then permeabilized with ice-cold ethanol for $30 \mathrm{~min}$ and stained with $200 \mu \mathrm{L}$ of Guava Cell Cycle reagent (Merck Millipore), containing propidium iodide (PI), for $30 \mathrm{~min}$ in the dark. At the end of the incubation, cells were analyzed via flow cytometry. 
All results are expressed as mean \pm SEM (Standard Error of the Mean). Differences among exposure conditions at different time point $(6,24,48 \mathrm{~h})$ were evaluated by One-way ANOVA repeated, followed by Bonferroni as post hoc test. For all statistical analysis, GraphPad InStat version 5.0 (GraphPad Prism, San Diego, CA, USA) was used and $\mathrm{P}<0.05$ was considered significant.

\section{Measurement of nitrites, nitrates and peroxides in cell culture medium}

Semi-quantitative analysis of nitrites $\left(\mathrm{NO}_{2}{ }^{-}\right)$, nitrates $\left(\mathrm{NO}_{3}{ }^{-}\right)$and peroxides $\left(\mathrm{H}_{2} \mathrm{O}_{2}\right)$ produced after exposure to plasma in $1 \mathrm{~mL}$ complete medium were performed by means of Quantofix ${ }^{\circledR}$ analytic strips. All the measurements were effectuated immediately after the end of the treatments.

\section{Results and Discussion}

\section{High Speed imaging and iCCD imaging of the plasma discharge}

A qualitative investigation of the plasma discharge produced during the treatment of $1 \mathrm{ml}$ of cell culture medium not containing Lymphoma cells was performed by means of HS and iCCD imaging; for the following operating conditions: PV $20 \mathrm{kV}$, PRF $500 \mathrm{~Hz}$, gap $1.25 \mathrm{~mm}$ (T1 case) and PV $20 \mathrm{kV}$, PRF $500 \mathrm{~Hz}$, gap $2.50 \mathrm{~mm}$ (T2 case). The described experimental setup, as well as the considered operating conditions, were identical to those adopted for biological tests.

Concerning HS imaging, two different frame rates were used, $100 \mathrm{fps}$ and $500 \mathrm{fps}$; the HS camera shutter was kept open and, subsequently, exposure time was imposed by the frame rate (Figure 5). Considering the PRF adopted in the experiments, images recoded at 500 frames/s show the discharge produced during a single pulse of the driving electrical signal, while images recoded at 100 frames/s are accumulated over 5 subsequent pulses. 

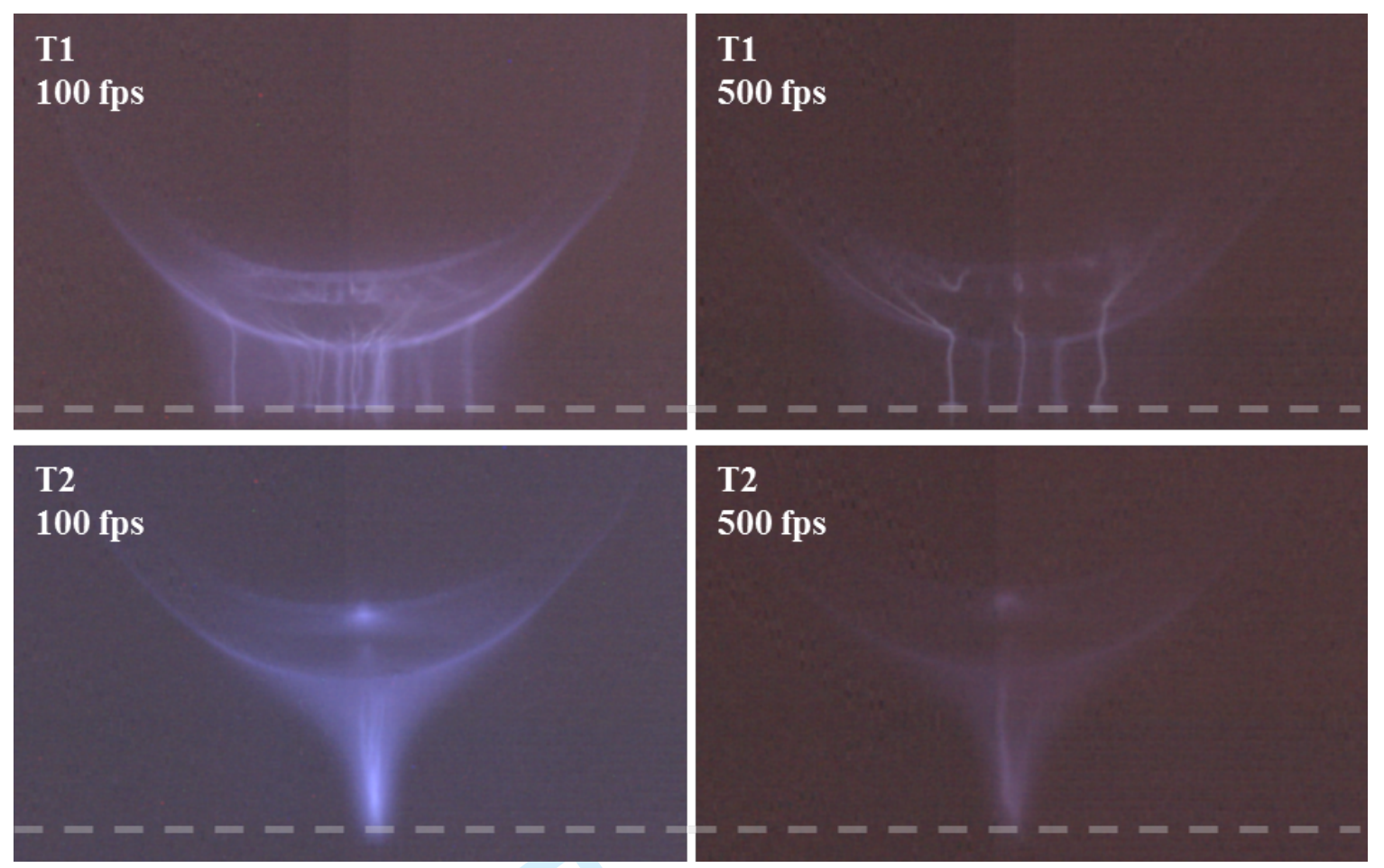

Figure 5. HS images of the plasma discharge during the treatment of culture medium (the dashed line indicates the culture medium surface) for both selected operating configurations (top: T1, bottom: T2). Acquisitions were realized at two different frame rates (left: $100 \mathrm{fps}$, right $500 \mathrm{fps}$ ).

The reported HS images immediately highlight the effect of a variation of gap width, and thus of electrical field in the gap, on the plasma discharge aspect; for the smallest gap width (T1 case), the discharge appears characterized by several microdischarges located close to the tip of the plasma source. In this case, for the longest exposure time (100 fps image), a faint glow appears in the gap region and a larger number of filaments are observed with respect to the image taken at $500 \mathrm{fps}$, as a consequence of the accumulation of 5 subsequent discharges; the comparison between images taken at $100 \mathrm{fps}$ and $500 \mathrm{fps}$ highlights also that during subsequent pulses, for the selected operating conditions, the microdischarges form in different locations, with no significant memory effect observed [26], possibly as a consequence of the adopted value of PRF and the unevenness of the liquid surface acting as a second electrode. When the gap between the plasma source and the culture medium surface is larger (T2 case), the plasma discharge appears completely different from the previous case, being characterized by a single filament located at the tip of plasma source, where the gap is the smallest and the

$$
\text { Wiley- } 10 \overline{\mathrm{CH}}
$$


electric field is the highest. The single filament has a funnel-like shape, which appears broader at the upper electrode, due to charge distribution and electric field distortion at the dielectric surface, and more collimated close to the culture medium surface; moreover, in case T2 images taken at different exposure times seem to show that filament produced during successive pulses are formed always in the same position, along the axis of the plasma source. iCCD imaging, being characterized by exposure times of few nanoseconds, allows for the investigation of the plasma behavior with greater time resolution than HS images [16-22], and was here used to investigate the temporal evolution of a single discharge event. Due to iCCD technology limitations, only one acquisition per voltage pulse can be gathered and thus the analysis of the discharge evolution along the voltage pulse is based on the assumption of repeatability of the plasma discharge characteristics in every high voltage pulse; this assumption was verified comparing three different acquisitions and observing that plasma evolution during the pulses was similar in all the cases. In our experiments, the exposure time was set at 3 ns (gate time) and the voltage pulse was scanned with time steps of 1 ns, obtained progressvely increasing the trigger delay time.

In Figure 6, eight subsequent frames representing the plasma evolution are shown for each operating condition ( $\mathrm{T} 1$ and $\mathrm{T} 2)$; for clarity purposes, the gate opening of the first (1, colored in green) and last acquisitions (8, colored in red) are plotted against the recorded voltage waveform in Figure 7. 

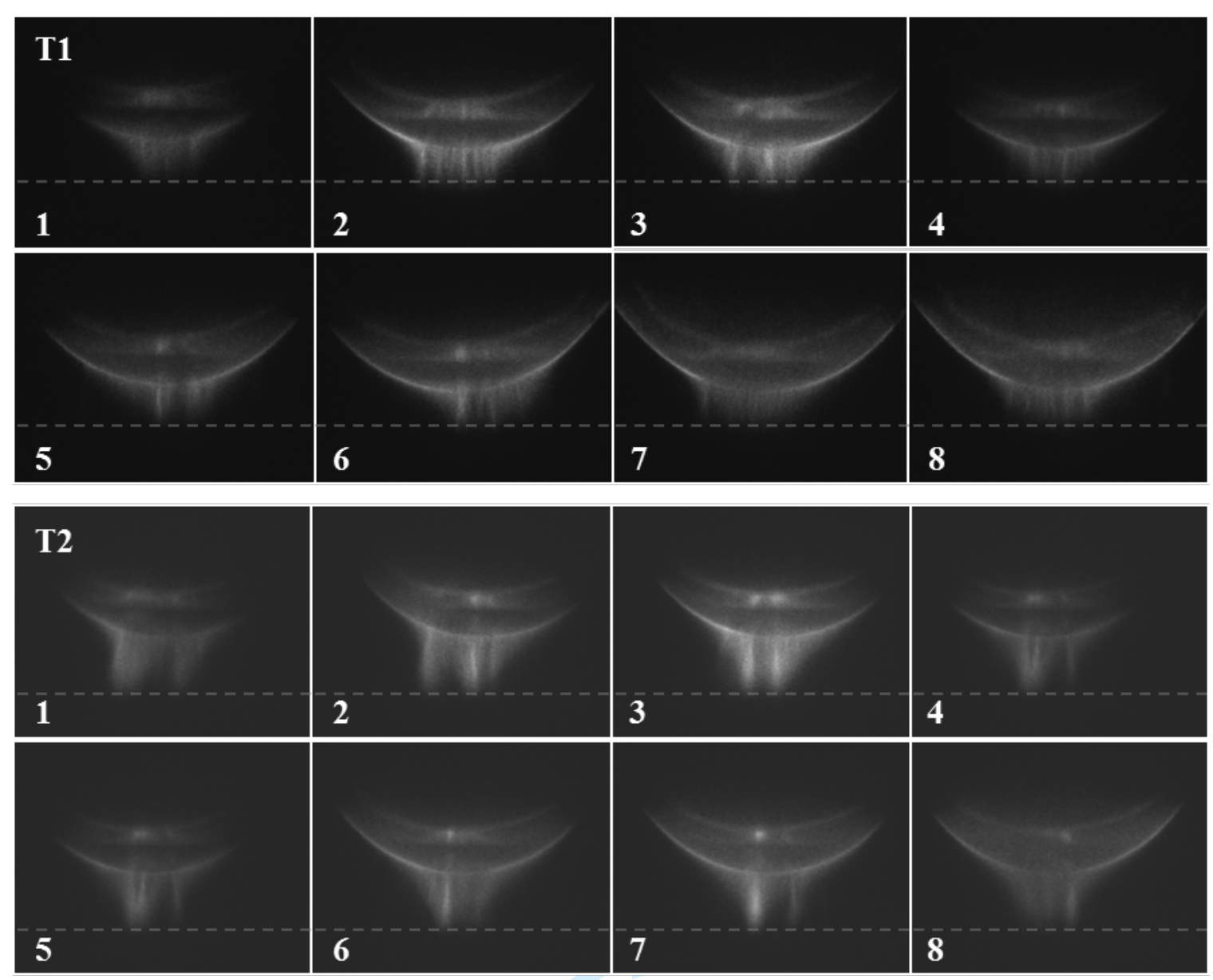

Figure 6. iCCD images depicting the temporal evolution along the voltage pulse of the plasma discharge formed in contact with $1 \mathrm{ml}$ of culture medium (the dashed line indicates the culture medium surface), for both operating configurations adopted for cancer cell treatment (T1, T2). The start of each acquisition ( $3 \mathrm{~ns}$ exposure) is delayed of $1 \mathrm{~ns}$ with respect to the previous one.

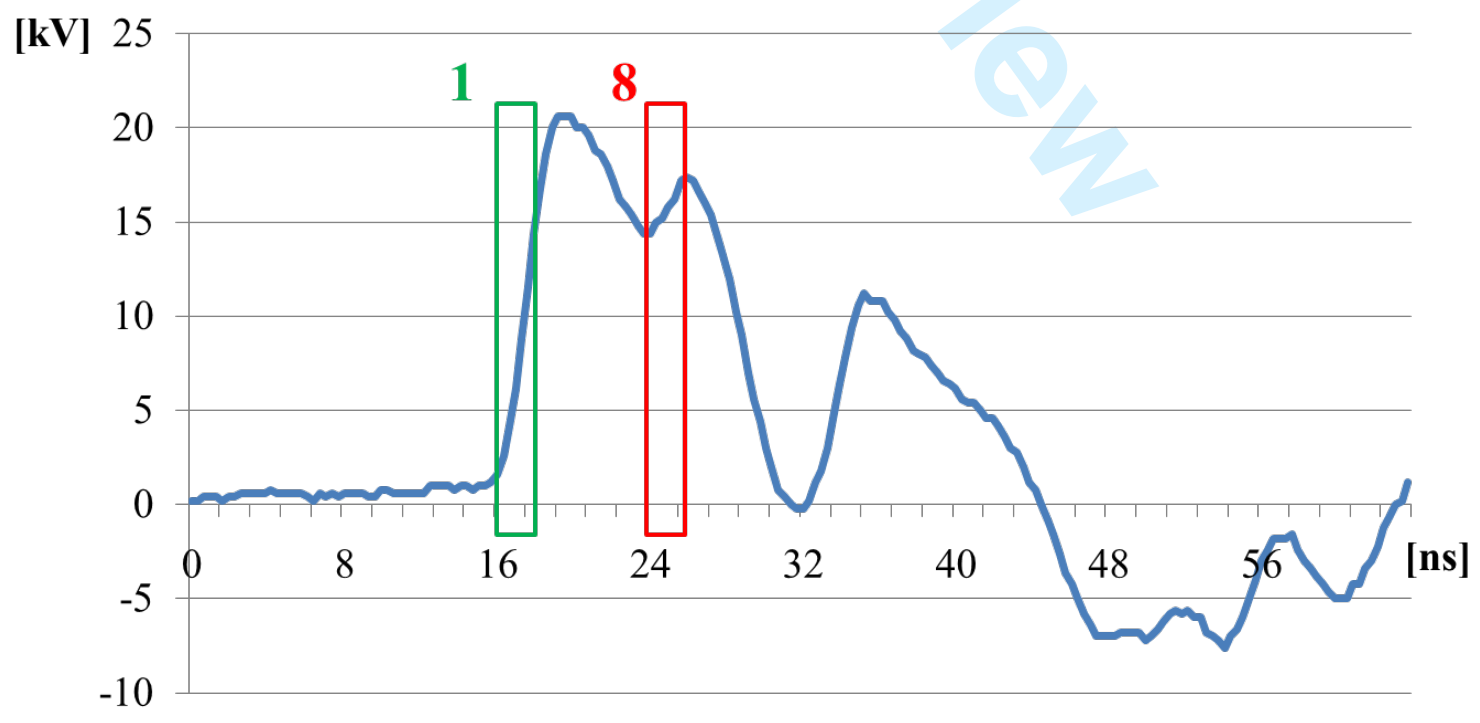

Figure 7. Measured voltage waveform with superimposed exposure gates for the first (1, green) and last $(8$, red) iCCD frames. 
From iCCD acquisitions, the discharge structures for $\mathrm{T} 1$ and $\mathrm{T} 2$ cases turn out to be more similar to each other than previously observed by means of HS imaging. Indeed, the first plasma luminous emission appears almost at the same time, corresponding to the initial part of the voltage ramp, in both cases; moreover, the third frame, collected in correspondence of the maximum peak voltage, is the most luminous for both T1 and T2 cases. Most interestingly, a multi-filamentary structure is observed in both operating conditions; while this behavior was already observed by means of HS imaging in T1 conditions, only a single filament along the axis of the plasma source could be seen for the T2 case in HS pictures. This is probably because in HS imaging acquisition no light signal intensification is applied, therefore the signal of short living or low emitting microdischarges could be shadowed by the presence of a longer living or higher emitting microdischarge; indeed, almost all iCCD images for T2 case show the presence of a microdischarge near the axis of the source, while other shorter living microdischarges appear and disappear in subsequent frames.

\section{Studies of cell viability, proliferation and cell-cycle progression for direct plasma treatment}

Plasma induced a decrease in cell viability after $48 \mathrm{~h}$ from treatment, as revealed by the number of cells permeable to 7-AAD, a fluorescent compound with strong affinity for DNA that remains excluded from viable cells with intact membrane. After $60 \mathrm{~s}$ of L5178Y plasma exposure at the distance of $1.25 \mathrm{~mm}$ the percentage of viable cells was $57.3 \%$ compared to $71.2 \%$ of untreated cells (Figure 8). The highest cytotoxic effect was induced by cells exposure to plasma for $120 \mathrm{~s}$ at the distance of $2.50 \mathrm{~mm}$ (43\% living cells compared to $71.2 \%$ of untreated cells) (Figure 8). 


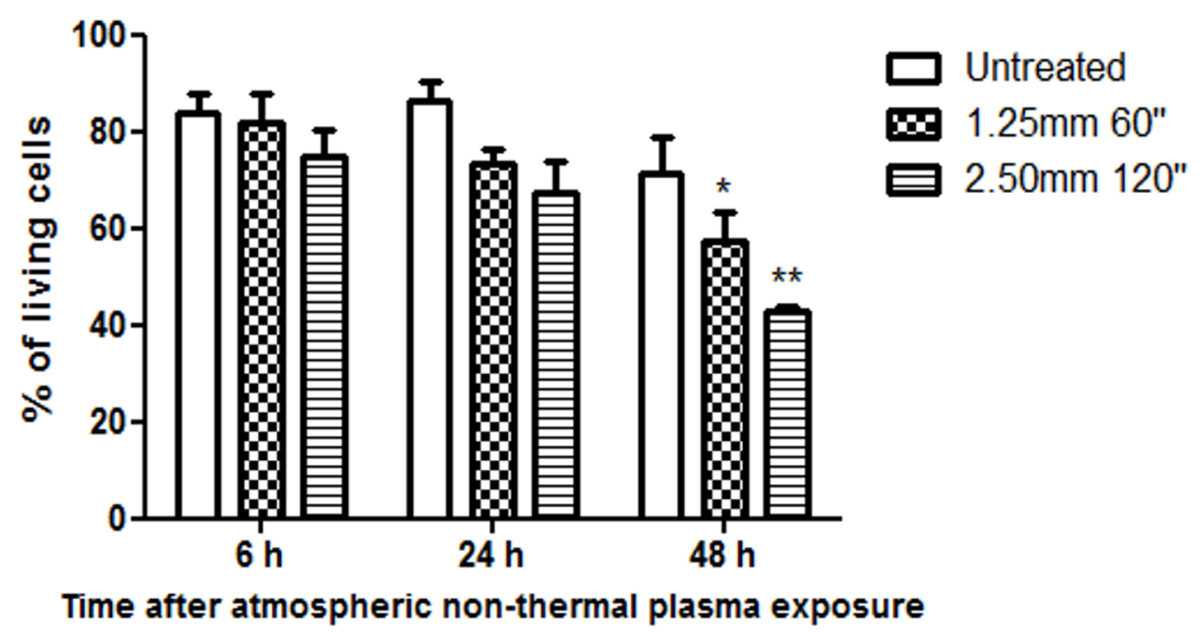

${ }^{*} \mathrm{P}<0.05$ and ${ }^{* *} \mathrm{P}<0.01$

Figure $8 . \%$ of living cells after 6,24 and $48 \mathrm{~h}$ from direct atmospheric non-equilibrium plasma exposure.

Furthermore, cold plasma affected cells proliferation both after 24 and $48 \mathrm{~h}$ from the exposure (Figure 9). The highest effect was observed at the exposure condition $2.50 \mathrm{~mm}$ for $120 \mathrm{~s}$, where it was possible to observe $36.7 \%$ proliferating cells after $24 \mathrm{~h}$ from the treatment and $30.0 \%$ after $48 \mathrm{~h}$ (Figure 9).

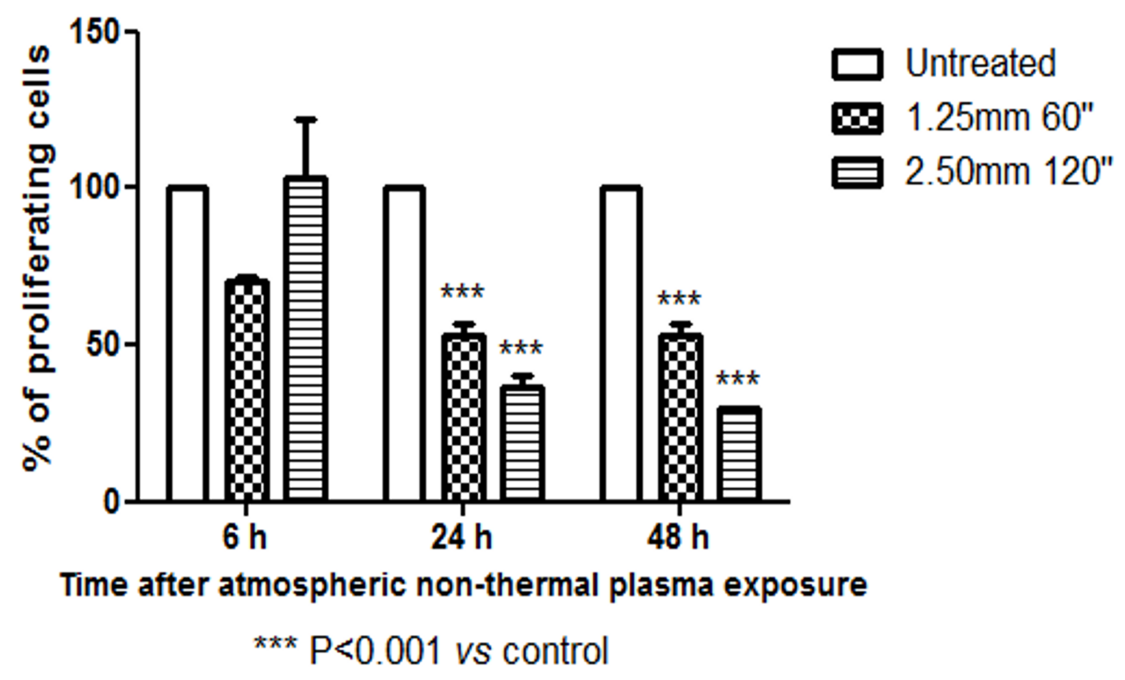

Figure 9. \% of proliferating cells after 6,24 and $48 \mathrm{~h}$ from direct atmospheric nonequilibrium plasma exposure.

In order to investigate non-equilibrium plasma effects on cell-cycle progression, cells were treated with a reagent containing PI, a red fluorescent intercalating agent that allows to evaluate DNA content. During cell-cycle S phase, cells duplicate their content of DNA that 
will be double in G2/M phase compared to G0/G1 phase, as well as PI fluorescence. After 24 $\mathrm{h}$ from the treatment, it was possible to observe an accumulation of cells in G2/M phase, as showed in Figure 10A, for both exposure conditions $(1.25 \mathrm{~mm}, 60 \mathrm{~s} 65.3 \%$ cells and 2.50 mm, 120 s 55.9\% cells vs 39.6\% of untreated cells) (Figure 10B). After 48 h from plasma exposure, the accumulation of cells in G2/M phase was statistically significant for the exposure condition $2.50 \mathrm{~mm}, 120 \mathrm{~s}(52.2 \%$ cells vs $42.8 \%$ of untreated cells) (Figure 10C).

A
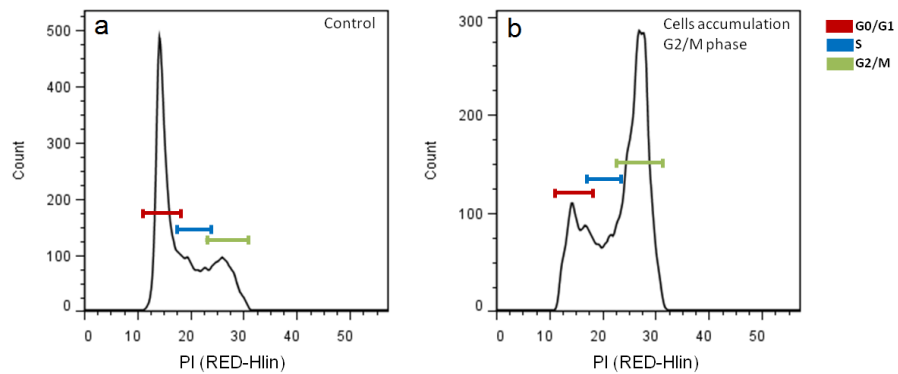

B
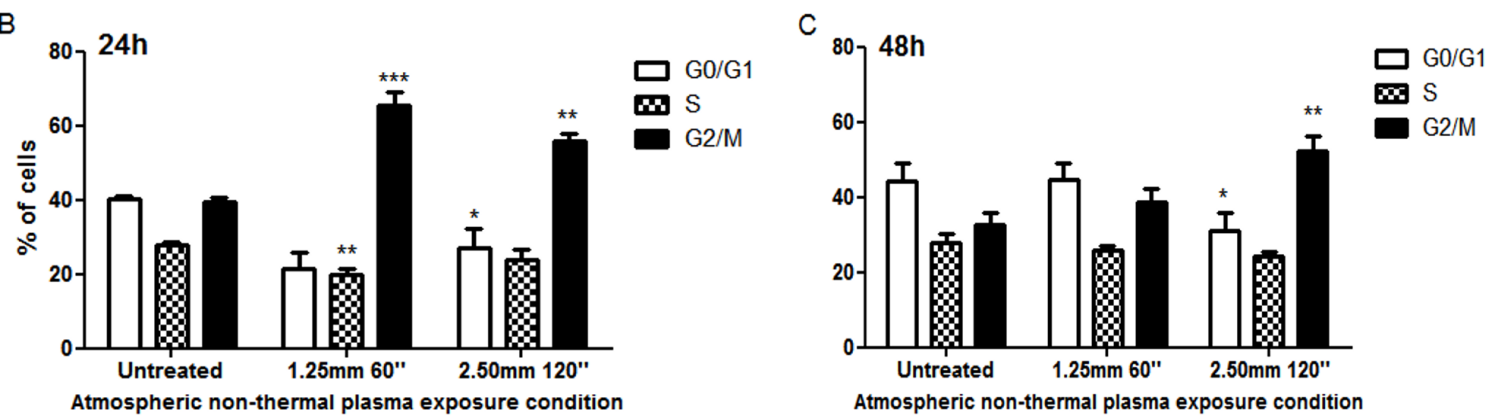

${ }^{*} \mathrm{P}<0.05,{ }^{*} \mathrm{P}<0.01$ and ${ }^{\star \star *} \mathrm{P}<0.001$

Figure 10. Fluorescence histograms representing cell-cycle distribution of untreated cells (Aa) and of cultures directly treated with plasma, where a plasma-induced $G 2 / \mathrm{M}$ phase accumulation is evident (Ab). Cell-cycle distribution after 24 (B) and $48 \mathrm{~h}$ (C) from atmospheric non-equilibrium plasma exposure.

On the basis of our results, the cell-cycle arrest is reversible for the $60 \mathrm{sec}$ and $1.25 \mathrm{~mm}$ condition; indeed, in that condition, we observed an accumulation of G2-cells at $24 \mathrm{~h}$ posttreatment but not at 48 -h post-treatment. This means that cells can overcome the plasmainduced cell-cycle arrest and start proliferating. The $120 \mathrm{sec}$ and $2.50 \mathrm{~mm}$ condition is able to induce a stronger antiproliferative effect, from which cells cannot rescue; in this case, we can conclude that the cell-cycle arrest induced by plasma is irreversible. 
Taken together, these results demonstrate that the growth inhibition of lymphoma cells induced by plasma treatment is imputable to cell death and cell-cycle arrest in which G2 accumulation is a key event. The simultaneous appearance of G2 block and cell death suggests that cell death is a primary direct effect due to plasma treatment, and not a secondary effect due to the cells' inability to overcome growth arrest and proceed through the cell cycle.

\section{Comparison of direct and indirect plasma treatment}

Results for cell viability after direct and indirect plasma treatment at different treatment times, PV $20 \mathrm{kV}$, PRF $500 \mathrm{~Hz}$ and gap $1.25 \mathrm{~mm}$ are reported in Figure 11. As revealed by the number of cells permeable to 7-AAD, the longer the treatment time (from $30 \mathrm{~s}$ to $120 \mathrm{~s}$ ) and the culture time after plasma treatment $(6,24$ and $48 \mathrm{~h})$, the higher the reduction in cell viability; no relevant difference can be observed between direct and indirect treatment results. Similar results were obtained with a gap of $2.50 \mathrm{~mm}$ and identical treatment times (data not shown). This suggests that the chemistry induced by plasma treatment in the culture medium plays the leading role in plasma reduction of cancer cells viability; similar considerations were previously reported by Vandamme et al. [27] and Mohades et al. [28], who compared the effects of direct and indirect treatment on glioblastoma U87MG and SCaBER bladder cancer cells, respectively.

\section{Indirect treatment}

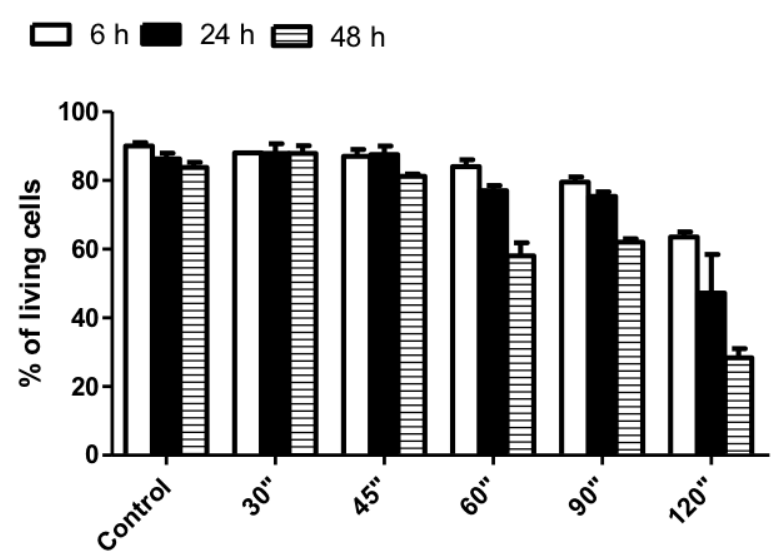

Atmospheric non-equilibrium plasma exposure time
Direct treatment

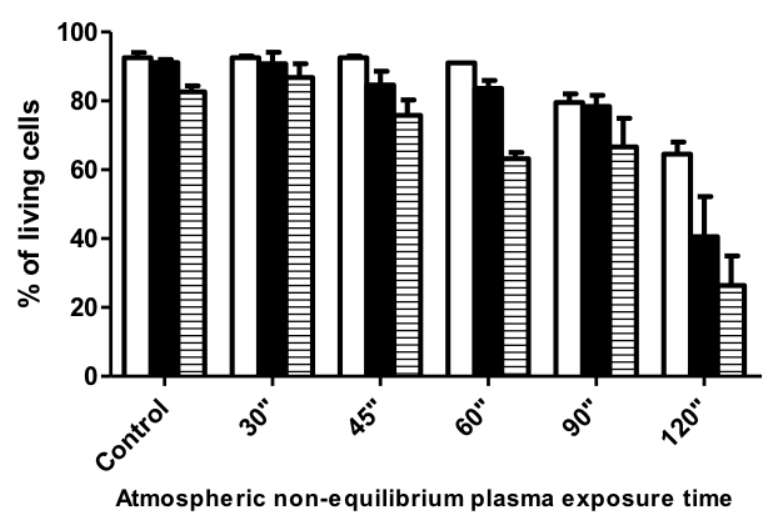


Figure $11 . \%$ of living cells after direct and indirect plasma treatment for different treatment times. Data were collected 6, 24 and $48 \mathrm{~h}$ after cells were added to atmospheric nonequilibrium plasma treated medium (indirect treatment) or $6,24,48 \mathrm{~h}$ after atmospheric nonequilibrium plasma exposure of cells (direct treatment). Operating conditions: PV $20 \mathrm{kV}$, PRF $500 \mathrm{~Hz}$ and gap $1.25 \mathrm{~mm}$.

\section{Measurement of nitrites, nitrates and peroxides in cell culture medium}

Results for the concentration of $\mathrm{NO}_{2}{ }^{-}, \mathrm{NO}_{3}{ }^{-}$and $\mathrm{H}_{2} \mathrm{O}_{2}$ produced in $1 \mathrm{~mL}$ of complete cell culture medium after plasma treatment, semi-quantitatively measured by means of analytic strips, are reported in Table 1. In particular, results for treatments carried out in the same operating conditions (T1 and T2) adopted for studies of cell viability, proliferation and cellcycle progression are presented; moreover, also results for plasma treatment performed with gap width $1.25 \mathrm{~mm}$ and treatment time $120 \mathrm{~s}$, which was shown in Figure 11 to induce the lowest cell viability among the tested treatments, are presented as a means of comparison and discussion.

Table 1. Nitrite, nitrate and peroxide concentrations in the as is and plasma treated cell culture medium. All treatments were performed at PV $20 \mathrm{kV}$ and PRF 500.

\begin{tabular}{lccc}
\hline Operating conditions & $\mathrm{NO}_{2}{ }^{-}(\mathrm{mg} / \mathrm{L})$ & $\mathrm{NO}_{3}{ }^{-}(\mathrm{mg} / \mathrm{L})$ & $\mathrm{H}_{2} \mathrm{O}_{2}(\mathrm{mg} / \mathrm{L})$ \\
\hline Untreated & 0 & 0 & 0 \\
$\begin{array}{l}\text { Gap 1.25 mm, } \\
\text { treatment time } 60 \mathrm{~s}(\mathrm{~T} 1)\end{array}$ & $5-10$ & $100-250$ & $3-10$ \\
$\begin{array}{l}\text { Gap 2.5 mm, } \\
\text { treatment time 120 s (T2) }\end{array}$ & $5-10$ & $100-250$ & $3-10$ \\
$\begin{array}{l}\text { Gap 1.25 mm, } \\
\text { treatment time 120 s }\end{array}$ & $10-20$ & $100-250$ & $3-10$ \\
\hline
\end{tabular}

For all the tested conditions, a significant increase of $\mathrm{NO}_{2}{ }^{-}, \mathrm{NO}_{3}{ }^{-}$and $\mathrm{H}_{2} \mathrm{O}_{2}$ can be observed with respect to the untreated cell culture medium. For the cases $\mathrm{T} 1$ and $\mathrm{T} 2$, the measured concentration of all reactive species fell in the same range; since viability, proliferation and cell-cycle progression tests have shown different results for conditions T1 and T2, we would have to conclude that the limited sensitivity of the analytic strips prevents us from drawing further conclusions on the relative importance of the various reactive species on the modulation of cell response to plasma exposure. Despite this limited sensitivity, a 
significantly higher nitrite concentration with respect to the $\mathrm{T} 1$ and $\mathrm{T} 2$ treatments was measured for the case with a $1.25 \mathrm{~mm}$ gap and for $120 \mathrm{~s}$, while nitrate and peroxide concentrations were measured in the same range. Nitrites were previously suggested to possibly have a significant role in plasma oncology [29] and to be linked to the reduction of cell viability after plasma treatment [30-31]; accordingly, we measured the highest concentration of nitrites for the case inducing the highest reduction of cell viability: considering only the $48 \mathrm{~h}$ culture times, the treatment performed with a $1.25 \mathrm{~mm}$ gap and for $120 \mathrm{~s}$ resulted in a percentage of viable cell of $26 \%$, while treatment $\mathrm{T} 1$ and $\mathrm{T} 2$ resulted in percentages of $57.3 \%$ and $43 \%$, respectively.

\section{Conclusion}

Atmospheric non-equilibrium pressure plasma has encountered a great interest as a novel antitumor agent since it was demonstrated by early works, both on in vitro and in vivo models, that the wide blend of chemical and physical reactive components could exert anti-tumor effects [32-37]. Beside few pioneering studies [5-6], plasma-cell interaction mechanisms are still mostly unsolved and thus are an extremely relevant subject of current cutting edge researches [38-39]. With the aim to contribute to garner knowledge on the fundamental aspects of plasma interactions with cancers cells, the effects of the plasma treatment on the viability, proliferation and cell-cycle distribution of L5178Y TK+/- clone (3.7.2C) cells of mouse lymphoma have been presented in this paper.

Plasma treatments were performed by means of a wand electrode DBD driven by unipolar nanosecond high voltage pulses, either in direct configuration, with cells exposed to plasma while suspended in DMEM, or indirect configuration, where cells were added to DMEM previously activated by plasma treatment. In direct configuration, two different sets of operating conditions were considered, varying the distance between the tip of the plasma source and the surface of the liquid medium and the treatment time; qualitative differences 
between the plasma discharges produced in the two operating conditions were highlighted by means of HS and iCCD imaging. Plasma treatment was observed to reduce the percentage of viable cells in both the evaluated operating conditions, with the highest cytotoxic effect for the case with longest exposure time and largest gap width. Moreover, plasma treatment was shown to significantly reduce cell proliferation and to induce a statistically significant accumulation of cells in $\mathrm{G} 2 / \mathrm{M}$ phase.

Furthermore, results for direct treatment were compared with results for indirect treatment of cancer cells: no differences were observed for cell viability in the two cases, suggesting that the leading role in plasma treatment of cancer cells is played by the reactive species produced in the culture medium. Semi-quantitative measurements of nitrites, nitrates and peroxides highlighted the production of significant concentrations of reactive species in the culture medium after plasma treatment; despite their sensitivity limitations, the adopted analytic strips hinted at a connection between nitrite concentration and the reduction of cell viability, supporting data and speculations presented in other works [29-31]. Therefore, future activities will be focused on a more detailed identification and quantification of the reactive species produced by plasma treatment in the culture medium and in the investigation of their role in the mechanisms of plasma interaction with cancer cells.

Acknowledgements: This work was partially supported by COST Action MP1101 "Biomedical Applications of Atmospheric Pressure Plasma Technology", by COST Action TD1208 "Electrical discharges with liquids for future applications" and by the 2007-2013 Emilia Romagna Regional Operational Programme (POR) of the European Regional Development Fund (FESR). 
Received: ((will be filled in by the editorial staff)); Revised: ((will be filled in by the editorial staff)); Published online: ((please add journal code and manuscript number, e.g., DOI: 10.1002/ppap.201100001))

Keywords: Cell-cycle analysis; cell viability; dielectric barrier discharge; lymphoma; plasma treatment of cancer

((maximum five; alphabetical order; not capitalized; plural; separated by semicolons; no full stop))

[1] A. Jemal, R. Siegel, J. Xu, E. Ward, CA Cancer J Clin 2010, 60, 277.

[2] D. Hanahan, R.A.Weinberg, Cell 2000,100, 57.

[3] A. Arcangeli, S. Pillozzi, A. Becchetti, Curr. Med. Chem. 2012, 19, 683.

[4] J. E. Karp, D. D. Ross, W. Yang, M. L. Tidwell, Y. Wei, J. Greer, D. L. Mann, T.

Nakanishi, J. J. Wright, A. D. Colevas, Clin. Cancer Res. 2003, 9, 307.

[5] M. Keidar, R. Walk, A. Shashurin, P. Srinivasan, A. Sandler, S. Dasgupta, R. Ravi, R.

Guerrero-Preston, B. Trink, Br J Cancer 2011, 105, 1295.

[6] M. Vandamme, E. Robert, S. Pesnel, E. Barbosa, S. Dozias, J. Sobilo, S. Lerondel, A. Le Pape, J.M. Pouvesle, Plasma Process. Polym. 2010, 7, 264.

[7] H. J. Lee, C. H. Shon, Y. S. Kim, S. Kim, G. C. Kim, M. G. Kong, New J. Phys. 2009, 11, 115026.

[8] B. Gweon, M. Kim, D.B. Kim, D. Kim, H. Kim, H. Jung, J.H. Shin,W. Choe, Appl. Phys. Lett. 2011, 99, 063701.

[9] M. Ishaq, S. Kumar, H. Varinli, Z. Han, A. E. Rider, M. D. M. Evans, A. B.

Murphy, K. Ostrikov, Mol. Biol. Cell 2014, 25(9), 1523.

[10] O. Volotskova, T.S. Hawley, M.A. Stepp, M. Keidar, Sci. Rep. 2012, 2, 636.

[11] T. Adachi, H Tanaka, S. Nonomura, H. Hara, S. Kondo, M. Hori, Free Radical Bio. Med. 2015, 79, 28. 
[12] H. Tanaka, M. Mizuno, K. Ishikawa, K. Nakamura, H. Kajiyama, H. Kano, Plasma Med. 2011, 1, 265.

[13] F. Utsumi, H. Kajiyama, K. Nakamura, H. Tanaka, M. Mizuno, K. Ishikawa, H. Kondo, H. Kano, M. Hori, F. Kikkawa, Plos One 2013, 8, e81576.

[14] G. Fridman, M. Peddinghaus, H. Ayan, A. Fridman, M. Balasubramanian, A. Gutsol, A. Brooks, G. Friedman, Plasma Chem. Plasma Process 2006, 26, 425.

[15] M. Boselli, V. Colombo, E. Ghedini, M. Gherardi, R. Laurita, A. Liguori, P. Sanibondi, A. Stancampiano, 2013 IEEE ICSD Bologna, Italy, June 30 - July 4, 2013.

[16] T. Shao, Z. Niu, C. Zhang, Y. Yu, H. Jiang, W. Li, P. Yan and Y. Zhou, IEEE Trans. Plasma Sci. 2011, 39, 11, 2062.

[17] H. Luo, Z. Liang, B. Lv, X. Wang, Z. Guan, L. Wang, Appl. Phys. Lett. 2007, 91, 221504.

[18] M. Teschke, J. Kedzierski, E.G. Finantu-Dinu, D. Korzec, J. Engemann, IEEE Trans. Plasma Sci. 2005, 33, 310.

[19] F. Massines, A. Rabehi, P. Decomps, R. B. Gadri, P. Ségur, C. Mayoux, J. Appl. Phys. 1998, 83, 2950.

[20] S. Bianconi, F. Cavrini,V. Colombo, M. Gherardi, R. Laurita, A. Liguori, P. Sanibondi, A. Stancampiano, IEEE Trans. Plasma Sci. 2014, 42, 2746.

[21] M. Boselli, V. Colombo, M. Gherardi, R. Laurita, A. Liguori, P. Sanibondi, E. Simoncelli, A. Stancampiano, IEEE Trans. Plasma Sci. 2015, 99, DOI: 10.1109/TPS.2014.2381854.

[22] R. Laurita, A. Stancampiano, M. Boselli, F. Cavrini, A. Liguori, M. Gherardi, V. Colombo, Biointerphases, under submission.

[23] S. F. Mirala, E. Monette, R. Bartnikas, G. Czeremuszkin, M. Latreche, M. R. Wertheimer, Plasmas Polym. 2000, 5, 63. 
[24] M. Boselli, V. Colombo, E. Ghedini, M. Gherardi, R. Laurita, A. Liguori, P. Sanibondi, A. Stancampiano, IEEE Trans. Plasma Sci. 2014, 42, 2744.

[25] M. Boselli, V. Colombo, E. Ghedini, M. Gherardi, R. Laurita, A. Liguori, P. Sanibondi,

A. Stancampiano, Plasma Chem. Plasma Proc. 2014, 34 (4), 853.

[26] U. Kogelschatz, Plasma Chem. Plasma Proc. 2003, 23, 1.

[27] M. Vandamme, E. Robert, S. Lerondel, V. Sarron, D. Ries, S. Dozias, J. Sobilo, D.

Gosset, C. Kieda, B. Legrain, J.-M. Pouvesle, A. Le Pape, Int. J. Cancer 2012, 130, 2185.

[28] S. Mohades, N. Barekzi, and M. Laroussi, Plasma Process. Polym. 2014, 11, 1150.

[29] D. B. Graves, Plasma Process. Polym. 2014, 11, 1120.

[30] A. R. Gibson, H. O. McCarthy, A. A. Ali, D. O’Connell, W. G. Graham, Plasma Process. Polym. 2014, 11, 1142.

[31] J. Liebmann, J. Scherer, N. Bibinov, P. Rajasekaran, R. Kovacs, R. Gesche, P. Awakowicz, V. Kolb-Bachofen, Nitric Oxide 2011, 24, 8.

[32] I. E. Kieft, PhD Thesis, Technische Universiteit Eindhoven, Eindhoven, September, 2005.

[33] G. Fridman, A. Shereshevsky, M. M. Jost, A. D. Brooks, A. Fridman, A. Gutsol, V. Vasilets, G. Friedman, Plasma Chem. Plasma Process. 2007, 27, 163.

[34] Z. Xianhui, L. Maojin, Z. Rouli, F. Kecheng, Y. Size, Appl. Phys. Lett. 2008, 93, 021502.

[35] G.-C. Kim, H. J. Lee, C.-H. Shon, J. Korean Phys. Soc. 2009, 27, 628.

[36] Y. Xu, X. Zilan, Z. Fei, Z. Shasha, L. Xinpei, Y. Guangxiao, H. Guangyuan, K. Ostrikov, Plasma Process. Polym. 2011, 9, 59.

[37] S. Kalghatgi, C. Kelly, E. Cerchar, J. Azizkhan-Clifford, Plasma Med. 2011, 1, 249.

[38] Y. Ma, C. S. Ha, S. W. Hwang, H. J. Lee, G. C. Kim, K.-W. Lee, K. Song, Plos One 2014, 9, e91947.

[39] N. Kaushik, N. Kumar, C. H. Kim, N. K. Kaushik, E. H. Choi, Plasma Process Polym. 2014, 11, 1175. 
The table of contents entry should be fifty to sixty words long (max. 400 characters), and the first phrase should be bold. The entry should be written in the present tense and impersonal style. The text should be different from the abstract text.

Fundamental aspects of plasma interaction with cancer cells are investigated using a wand electrode DBD driven by nanosecond HV pulses. Viability, proliferation and cellcycle distribution of mouse lymphoma cells are measured after plasma treatment. Results of cell viability for direct and indirect plasma treatments are compared. HS and iCCD images of plasma discharges generated under the operating conditions adopted in biological experiments are presented.

Matteo Gherardi*, Eleonora Turrini, Romolo Laurita, Elena De Gianni, Lorenzo Ferruzzi, Anna Liguori, Augusto Stancampiano, Vittorio Colombo, Carmela Fimognari

Title Atmospheric non-equilibrium plasma promotes cell-death and cell-cycle arrest in a lymphoma cell line

ToC figure ((Please choose one size: $55 \mathrm{~mm}$ broad $\times 50 \mathrm{~mm}$ high or $110 \mathrm{~mm}$ broad $\times 20 \mathrm{~mm}$ high. Please do not use any other dimensions))
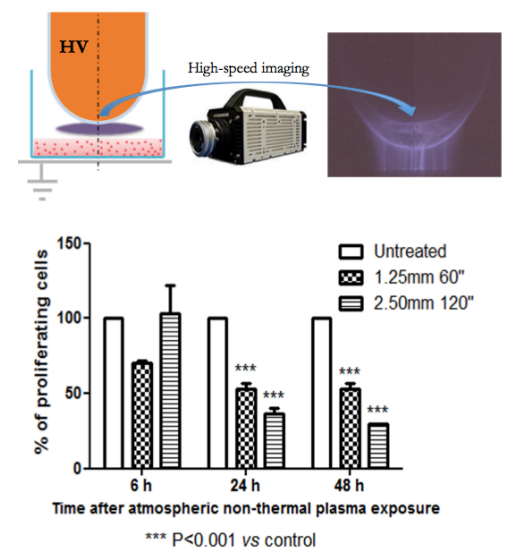

Copyright WILEY-VCH Verlag GmbH \& Co. KGaA, 69469 Weinheim, Germany, 2011. 